\title{
El tiempo de una imagen: el tiempo-con
}

\author{
Time of an Image: The Time-With \\ O tempo de uma imagem: o tempo-com
}

\section{Raúl Antelo}

UNIVERSIDADE FEDERAL DE SANTA CATARINA, BRASIL

Profesor en la Universidade Federal de Santa Catarina, Florianópolis. Doctor en Literatura por la Universidad de Buenos Aires. Autor de Literatura em Revista (Ática, 1984), Na ilha de Marapatá (Hucitec-INL, 1986), foao do Rio: o dândi e a especulaçao (Timbre-Taurus, 1989), Parque de diversoes Aníbal Machado (Ed. da UFMG-Ed. da UFSC, 1994), Objecto Textual (Memorial da América Latina, 1997), Algarabía. Discursos de Naçao (Ed. da UFSC, 1998). Correo electrónico: antelo@iaccess.com.br

\section{Artículo de reflexión}

Documento accesible en línea desde la siguiente dirección: http://revistas.javeriana.edu.co doi: 10.11144/Javeriana.cl19-38.tdui 


\section{Resumen}

Para conceptualizar

lo contemporáneo es imprescindible comprender que hay en el arte una forma de pensamiento que se ofrece en la forma de no-pensamiento, así como, inversamente, hay un no-pensamiento que alimenta al pensamiento $\mathrm{y}$, en última instancia, le confiere una potencia peculiar. Ese no-pensamiento -el reino de la imagen-no es una nada sino un vacío. No es sólo ausencia de pensamiento, sino presencia efectiva de lo otro y lo heterogéneo; en otras palabras, es equivalencia entre pensamiento y no-pensamiento, es decir, entre logos y mythos. La Modernidad es así no ya negatividad dialéctica sino heterología diseminada.

Palabras clave: imagen; ficción; sobrenaturaleza; artificio

\section{Abstract}

To conceptualize the contemporary it is essential to understand that in art there is a line of thought offered as a line of non-thought just like, inversely, there is a non-thought that feeds thought and, ultimately, grants it a particular potency. This nonthought -the realm of image- is not a nothing, but a void. It is not only the absence of thought, but the effective presence of the otherness and heterogeneity. In other words, it is the equivalent between thought and nonthought, that is, between logos and mythos. In this way, Modernity is no longer dialectic negativity, but disseminated heterology.

Keywords: image; fiction; beyond nature; artifice

\section{Resumo}

Para conceitualizar o

contemporâneo é imprescindível compreender que tem na arte uma forma de pensamento que se oferece sob a forma de não-pensamento, assim como, inversamente, tem um não-pensamento que alimenta o pensamento e, em última instancia, outorga-lhe uma potência peculiar. Esse não-pensamento -o reino da imagem- não é um nada senão um vazio. Não é apenas ausência de pensamento, senão presencia efetiva do outro e do heterogêneo; em outras palavras, é equivalência entre pensamento e não-pensamento, ou seja, entre logos e mythos. A Modernidade é assim não já negatividade dialética mais heterologia disseminada.

Palavras-chave: imagem; ficção; sobrenatureza; artifício

RECIBIDO: 27 DE MAYO DE 2014. EVALUADO: 14 DE JULIO DE 2014. DISPONIBLE EN LÍNEA: 01 DE JULIO DE 2015

\section{Cómo citar este artículo:}

Antelo, Raúl. "El tiempo de una imagen: el tiempo-con". Cuadernos de Literatura

19.38 (2015): 376-399. http://dx.doi.org/10.11144/Javeriana.cl19-38.tdui 
ES CONSENSUAL CONSIDERAR el mundo contemporáneo como una ficción sin autor y sin afuera. En el plano de la crítica, tal convicción se corresponde con el pasaje de lo orgánico a lo inorgánico, de la obra al texto, y de la acción a la inoperancia. La imaginación y sus dispositivos (Agamben, Che cosề un dispositivo?). Arjun Appadurai ha mostrado que, lejos de funcionar como ocioso pasatiempo para las élites, la imaginación es un campo organizado de prácticas masivas, o sea, una forma de trabajo culturalmente organizada, y ello nos lleva a reconsiderar la dimensión pública de las imágenes, decididas tanto por los medios como por las migraciones -dos fenómenos de masas-. Lo público, tradicionalmente fruto de la separación entre lo privado y lo social, no sólo ya no se opone a la imaginación, digamos así, individual o "privada", sino que la constituye, con lo cual es público ahora todo aquello que se piensa, simultáneamente, fuera y dentro de la acumulación. Creo reconocer, sin embargo, en lo tocante a imaginarios públicos y políticas del presente, dos vertientes críticas. Por un lado, la herencia teórica de Frankfurt prioriza la cuestión de la autonomía, porque sus mentores, entre ellos Walter Benjamin, estaban preocupados, fundamentalmente, con la reproducción técnica que afectaría a las subjetividades, de allí en más, anestesiadas; pero también es innegable que, después de Foucault, Deleuze y Derrida, ya no se puede ignorar que al cuestionar el falso movimiento de la historia, la crítica dialéctica no dejó de reconocer también que se hallaba ella misma en un teatro. El énfasis pasó entonces a recaer no ya en la reproducción sino en la repetición de valores y formas. Ese es el auténtico theatrum philosophicum de la mundialización (Foucault). En ese escenario postautonómico ya no se debaten formas sino fuerzas; esas fuerzas se llaman imágenes. Son enigmas en los que, de la superposición (el con) de la tradición y la ruptura, lo trágico y lo farsesco, surge lo nuevo. El teatro de la repetición ya no es el teatro de la representación, así como el movimiento de las imágenes ya no comporta un concepto formal de globalización sino el modo en que, bajo su régimen, se producen los cuerpos.

\section{Pensar por imágenes}

Las imágenes no son hechos ${ }^{1}$. Por eso, algunos de los críticos de la autonomía se caracterizan por pensar por imágenes. Uno de ellos es Giorgio Agamben, gran lector de Benjamin, quien, antes incluso de El reino y la gloria (2007), ha

1 Franco Rella reitera que "le immagini non sono fatti" pero también nos alerta que no sabemos qué imágenes los jóvenes elaboran en relación a sus experiencias más íntimas. "Ma abbiamo idea delle sue immagini? Abbiamo noi immagini attraverso cui leggere in questo anche frammentariamente una qualche storia o un qualche senso?" (Rella, 2004 138). 
retornado a Aby Warburg y ha constatado, en Mnemosyne, nombre de ese atlante con memoria (mnemo-syn) que debía sostener el globo, un modo de aislar la fórmula de expresión, la Pathosformel, de la humanidad occidental. Una de ellas, en particular, la ninfa warburguiana, reposa sintomáticamente en la ambigüedad estructural de la imagen. Como subraya Agamben:

La ninfa è l'immagine dell'immagine, la cifra delle Pathosformeln che gli uomini si trasmettono di generazione in generazione e a cui legano la loro possibilità di trovarsi o di perdersi, di pensare o di non pensare. Le immagini sono, pertanto, un elemento decisamente storico; ma, secondo il principio benjaminiano per cui si dà vita di tutto ciò di cui si dà storia (e che qui si potrebbe riformulare nel senso che si dà vita di tutto ciò di cui si dà immagine), esse sono, in qualche modo, vive. (Ninfe)

La ninfa nos permite, entonces, pensar que el tiempo de la globalización sólo puede ser un tiempo-con, un tiempo no-cronológico sino anacrónico. Lo fundamental de esa peculiar concepción del tiempo no es tanto la sintonía como la co-esencia, la coexistencia gracias a la cual el anacronismo se redefine como participación temporal en la temporalidad, es decir, como una hiper-temporalización, infinita y potencializada, del evento singular. Los trabajos de Georges Didi-Huberman son un excelente ejemplo de esa perspectiva de análisis. Más recientemente, en Signatura rerum, Agamben se explaya y nos amonesta: la manera menos creativa de leer los despliegues de Mnemosyne consiste en verlos como un repertorio iconográfico en que la cuestión sería el origen y evolución de un tema. Lo más pertinente, sin embargo, es reparar que ninguna de esas imágenes es original, así como ninguna de ellas es réplica o reproducción pasiva de una matriz, de lo que se deduce ser indecidible el estatuto de creación y acto, original y ejecución, ya que esas imágenes son híbridos de arquetipo y fenómeno. "Ogni fotografia è l'originale, ogni immagine costituisce l'arché, è, in questo senso, arcaica; ma la ninfa stessa non è né arcaica né contemporanea, è un indecidibile di diacronia e sincronia, unicità e molteplicità" ("Signatura rerum. Sul metodo", 2008a 31). Esa imagen, la ninfa, es el paradigma, un esquema vacío, un Ur-fenómeno de la que cada ninfa singular es ejemplo pleno.

Muchas veces Giorgio Agamben ha dejado claro que considera esa ninfa, la imagen, un simple punto de la nada, una nada de nada, un vacío o habladuría fabulosa en que el autor, como por lo demás ya anticipará también Foucault, no es nada más que un gesto, una máscara o ausencia, una energía a través de la cual se derrama, sin cesar, el lenguaje irrefrenable. Es porque la subjetividad ficcional cristaliza, provisoriamente, en ese punto de la nada, ya sea como voz del lenguaje, 
ya como cuerpo de la imagen, que ese punctum puede, al fin y al cabo, anhelar un cuerpo y una carne como soportes provisorios para su inútil habladuría, antes de sumirse para siempre en el silencio de la historia (Identificación y desidentificación... 87). Con esa concepción, Agamben retoma ciertas articulaciones entre lo arcaico y lo actual, exploradas ya por la antropología a comienzos del siglo XX. A ese respecto, recordemos, en efecto, que Alfred Métraux, estudioso de la antropofagía tupi-guaraní y de los ritos de sacrificio vudú, asoció, por ejemplo, las ceremonias culturales captadas en Bolivia entre los Uro-Chipayas a un $a$ priori histórico, como diría Mauss, el del potlatch o don. En el trueque y en la obligación creadora de vínculo de esa cultura, muy anterior a la aymará, Métraux reconocía, junto a su amigo Bataille, un poder de singularización, un modo de participación e incluso, anticipándose a los argumentos de Derrida, veía en ellos un pensamiento del ser que eran, en verdad, un pensamiento acerca del tiempo, el de un tiempo-con. A partir de esos conceptos, el mismo Métraux analizaría en un libro dedicado a la isla de Pascua (1995) unas misteriosas inscripciones en tablas de madera, unos signos parlantes llamados kohau rongorongo, que, durante muchos años, intrigaron a viajeros y etnógrafos; Métraux concluye, a diferencia de la lectura funcionalista por entonces dominante, que no se trataba, en el caso de esas enigmáticas figuras, de una auténtica escritura y por lo tanto del umbral de la historia para esa cultura, sino de simples fórmulas mnemotécnicas que recién más tarde adquirirían valor sagrado para sus usuarios. Métraux llegaba a ese convencimiento porque, a la manera mimológica de Mallarmé, leía tales inscripciones a partir de una muy precisa concepción del lenguaje, la de un puro espacio de la ficción, y no veía en él un instrumento de comunicación o fundación de comunidad. No hay razón en el lenguaje, hay tan sólo juegos de poder.

$\mathrm{Al}$ igual que los poetas modernos atravesados por el luto y el trauma, Métraux evaluaba el olvido como el auténtico ritual de fundación de una literatura, como si ésta buscase, a través de la amnesia, reanudar los vínculos con el improbable origen, y como si la palabra misma no dispusiese de ninguna archè para afianzar sus fundamentos. Si los etnógrafos funcionalistas interpretaban esas imágenes, grabadas en las maderas, como una escritura, como un remedio contra la ausencia, la tesis del lenguaje como memoria, propuesta por Métraux, buscaba en el olvido, sin embargo, dos cosas: ciertamente un remedio, pero también un don para la falta de fundamento de la literatura. En la perspectiva autonomista, el mito entraba en escena para que la pérdida del origen no fuera completamente obliterada y pudiese ser conmemorada como formación de una literatura en busca, precisamente, de origen. Pero según la concepción mnenónica o postautomista, aquello que define a la literatura, al carecer de un marco fundacional inequívoco 
es, por el contrario, la infinita oscilación en su inefabilidad. Tales inscripciones son, como diría Ludmer, realidadficción, y otra no es la consistencia paradojal de la máquina mitológica.

Si para esas culturas el origen de la palabra no constituye en sí un problema, ello se debe a que el lenguaje circula en ellas como un hecho de lengua, de la que cada enunciado específico es tan sólo un anillo del don, mientras la lengua de la literatura, en cambio, falta siempre en su lugar. La poesía -dice Nancysólo tiene lugar a partir del momento en que tiene lugar (Fazer, a poesia 9). Por eso, en relación con el lenguaje, el artista moderno se encuentra siempre en la situación aporética de tener que pronunciar una palabra o sostener un habla, cuya lengua le es completamente ajena o ausente. De allí deriva, en suma, una de las más agudas paradojas de lo moderno: la de tener que conciliar, en la obra, su contemporaneidad; es decir, su pertenencia a los actos de habla del presente aunque su procedencia se retraiga al más remoto origen, y ello muestra asimismo que la obra, aun cuando sea inspirada por el pasado de la lengua, no deja de operar, simultáneamente, sobre el recuerdo de su mismo presente ${ }^{2}$. En ese punto, punto de la nada, se apoya pues Agamben para responder a la pregunta sobre lo contemporáneo (2008b).

A partir de esa paradoja, cabe pensar que en la literatura contemporánea hay pensamiento en la forma del no-pensamiento pero, inversamente, hay un nopensamiento que irriga al pensamiento $y$, en última instancia, le confiere a éste una potencia específica. Ese no-pensamiento no es una nada. Es un vacío. No es sólo ausencia de pensamiento sino presencia efectiva de su opuesto, es decir, equivalencia entre pensamiento y no-pensamiento, entre logos y mythos. En la presencia, a través de la creación, ese infinito sucede en lo finito. No es una individuación ni una generación, mucho menos una producción o mediación dialéctica. Es finito porque no sale de sí ad extra, está excavado en sí mismo, por su retiro que da lugar a la abertura donde se disponen los singulares finitos. Y es esa abertura como nada, que no se ofrece ni se da, sino que es un ser-con, la que conforma la

2 En un ensayo sobre el exotismo en Victor Segalen, Agamben señala que toda palabra literaria es exótica ya que proviene "da un'origine remota; ma per questo stesso motivo (...), la parola letteraria è fatalmente abolita, nel senso etimologico del termine, cioè: venuta di lontano (aboleo). Ecco il senso del gioco di oblio e rammemorazione che Segalen assegna come luogo allo scrittore: come per il mimo, del quale Mallarmé ci dice che agisce 'entre la perpétration et son avenir: ici, devançant, là remémorant, au futur, au passé, sous une apparence fausse de présent', così si può dire che lo scrittore 'installe, ainsi, un milieu pur, de fiction"' (Agamben, 1974 161). El ensayo fue recogido en el último libro de Agamben, La potenza del pensiero. Saggi e conferenze. Vicenza: Neri Pozza, 2005. 191-204. 
disposición del mundo ("La creación del mundo o la mundialización" 82-83). Por tanto, la potencia del pensamiento se corresponde con una escritura que no es sólo manifestación de la palabra, sino retirada o ausencia de ella misma en acto; ex acta, como la poesía. Decía Bataille que el pintor está condenado a complacer y que, por ningún medio, podría convertir a su obra en objeto de aversión.

Un espantapájaros tiene la finalidad de asustar a los pájaros, alejarlos del campo donde está enclavado, mientras que el cuadro más terrible está allí para atraer a los visitantes. Un suplicio real también puede despertar interés, pero en general no podría decirse que tenga el mismo fin: esto ocurre por un conjunto de razones; aunque en principio sus fines difieren poco de los espantapájaros: a la inversa del objeto de arte, se ofrece ante la vista para alejar del horror que expone. Mientras que el supliciado de los cuadros ya no intenta amonestarnos. El arte nunca se encarga de la tarea del juez. Por sí mismo no despierta interés en horror alguno: ni siquiera es imaginable. (...) Cuando el horror se ofrece a la transfiguración de un arte auténtico, lo que está en juego es un placer, un placer fuerte pero placer al fin. (Identificación y desidentificación... 117)

Es decir entonces que la acción del artista contemporáneo, presente como ausencia, consiste en hablar y callar al mismo tiempo ${ }^{4}$ y esa bipolaridad le define, al fin de cuentas, un lugar -el del síntoma-, una coincidencia, algo que cae con otra cosa, donde lo relevante no es tanto la caída, el incidente o incidencia, sino el con, la conexión o red que ese abandono suscita. Como síntoma, pues, podríamos entonces definir la lectura o com-mentario ${ }^{5}$ como caída u ocaso del sentido con

3 El mismo Bataille es consciente de que el horror fue inimaginable pero no es menos cierto que, en la Edad Media, la imaginería religiosa lo hizo palpable con el infierno, porque, precisamente, el arte no estaba diferenciado de la enseñanza, no había sido autonomizado (Bataille, 2001 117).

4 La trayectoria de la poesía, en particular la de Oliverio Girondo, es ilustrativa en este punto. Tras su Espantapájaros, dispositivo poético para asustar y alejar a los desprevenidos de un campo donde está enclavado y del cual emergen nuevas alternativas, el poeta intenta una palabra de muerte situada en el entre-lugar de verdad y poder de lo nuevo, Interlunio, hasta descubrir que la auténtica experiencia se diluye como glosolalia en la masmédula del lenguaje.

5 En "La des-obra como ready-made" tuve ocasión de señalar que, a mi juicio, una de las opciones de la crítica del presente consiste en el abandono de la interpretación en favor del comentario. "La interpretación trabaja con el sentido, pero con un sentido dado, intencionado, original, histórico, adecuado o auténtico. Busca fijarlo, agotarlo. Quien comenta, en cambio, quiere promover la integración de contextos culturales antagónicos, anacrónicos o distópicos, a los cuales les ofrece un puente, un vínculo, un suplemento. El comentario depende, sin duda, de la interpretación, está subordinado a ella, pero allí donde la interpretación concluye, el comentario inconcluye. El comentario no se puede callar. Lo suyo, como diría Jabès, es comment-taire. Hay, por tanto, una 
otro tiempo o, al mismo tiempo, con otros sentidos ${ }^{6}$. Symptôma, caída, coincidencia, acontecimiento fortuito, encuentro llamado al desencuentro, tyché (Derrida, "Mes chances..." 1987).

Es bueno no perder de vista, llegados a este punto, que la teoría de la antropofagia ritual o del sacrificio vudú de Métraux subyace a varias manifestaciones de los intelectuales del círculo bataillano aplicados lectores de Nietzsche, tales como la de Roger Hervé, ilustrada por imágenes del techcatl (piedra sacrificial), reunidas pioneramente por Bernal Díaz del Castillo en la Historia verídica de la conquista de la nueva España (Sacrifices Humains du Centre-Amérique 205-231); la de Ralph von Koenigswald, con cabezas jíbaras (Têtes et crânes 353-358); la de Michel Leiris y sus máscaras fúnebres (Le caput mortuum ou la femme de l'alchimiste 21-26); o la de Georges Duthuit (25-39), con su cabeza mundurucá o los grabados de antropofagia tupinambá de Théodore de Bry que ilustran el libro de André Thévet, hasta llegar a la atracción de Bataille por el suplicio chino. Esta escena, franqueada por su analista, el doctor Borel, y que suscita su análisis de la mutilación sacrificial de Van Gogh es, fundamentalmente, una de sus obras

tarea finita de la interpretación y una tarea infinita del comentario. La topología de la interpretación busca jerarquizar entre lo visible y lo invisible. El comentario, sin embargo, no persigue nada más allá, más atrás o subyacente a los hechos mismos. Es lateral. Se ofrece como para-deigma. O como una fórmula, tal como diría Deleuze a propósito de Bartleby. Pero el concepto mismo de comentario (la forma) se equivale al contenido (la práctica) de su lectura y esa equivalencia entre significante y significado, recordemos, es definitoria del principio mismo de indiferencia ética. (...) Ahora bien, comentario viene de comminiscor, imaginar, verbo compuesto de cum y mens, que no es sólo mente o razón sino memoria. O sea que comentar es conmemorar. Como memorial, el comentario equivale al cuaderno de notas, al diario, o sea a aquellas anotaciones, realizadas al margen de un texto, que constituyen su marginalia, haciendo que el texto dialogue así con la historia. En ese sentido son auténticos comentarios los balbuceos de la vanguardia latinoamericana, registrados en cuadernos: Cuaderno San Martín, Primeiro caderno do aluno de poesia Oswald de Andrade, los cuadernos de viaje de Oliverio Girondo, sus Calcomanías, meras imágenes de contacto, o las Metamorfosis del dadaísta Jacques Edwards, el escritor chileno Joaquín Edwards Bello. Recordemos, además, que commentum, en Roma (...) equivalía a ficción, a cosa imaginada, a plano o proyecto. De donde, ante esa concepción fragmentaria de la obra de arte, nos deparamos, pues, no sólo con lo irrepresentable, sino también con lo inmemorial". Por lo demás, fue a través del nominalismo que la vanguardia dadaísta intuyó que sonidos y contactos eran mejores vehículos que las imágenes para expresar ese intersticio dimensional infraleve. El lenguaje como nueva tactilidad se vuelve entonces herramienta indispensable para captar la pluridimensionalidad de la experiencia (Antelo, Raúl, "La des-obra como ready-made" en Premat, Julio (ed.), "Quimeras" GAHIERS DE LI.RI.CO. n 4, Saint Denis, Université Paris 8, 2008).

6 Interpretar o descifrar el texto -nos dice Nancy- no quiere decir llevar la lectura hacia el sentido sino, al contrario, recomponer la cifra de la letra. No significa extraer el significado de su envoltorio sino desarrollar la intriga: explicar pero replicando el despliegue sobre sí mismo (Nancy, 2006 31-2). 
más emblemáticas, Las lágrimas de Eros. Son imágenes de acefalía. Recordemos asimismo que esa concepción del corps morcelé llevará a Lacan a hablar de tres registros, lo imaginario, lo simbólico y lo real, equiparados en jerarquía, y uno de los críticos más atentos a las profanaciones lacanianas, Roland Barthes, extraerá de esa tradición su teoría de la imagen como punctum, es decir, como vacío, como neutro. Que pese a todo estamos ante imágenes pero también ante el tiempo (Cfr. Didi-Huberman), y que de ese punto de la nada, en fin, rescatará Agamben la noción de imagen como phantasmata, un hiato o vacío temporal que define, en última instancia, los movimientos de la historia como creaciones de una sobrenaturaleza.

Precisamente en una versión abandonada de La parte maldita, Georges Bataille aborda ese abismo conceptual que, más tarde, Agamben llamaría el reino y la gloria:

El abuso que los mexicanos hacían de la muerte nos sitúa ante un abismo. Un abismo al que sin duda seguiremos acercándonos siempre, atraídos por el horror, pero de momento quiero apartarme de él y no considerar más que la gloria, que era lo único que los mexicanos perseguían. Los mexicanos no perecían en su propio abismo. En rigor podría decirse que a la llegada de Cortés, México se hundió, pero eso sólo llegó a suceder un día. México vivió hasta el final ebrio de gloria. Pero no como en nuestros días: entonces una verdadera tragedia y un sentimiento de ironía aparecían fuertemente mezclados. Para un mexicano la gloria no estaba relegada, como para nosotros, no era una cosa aparte de la vida cotidiana. No era ni ostentosa ni superficial. Muchos de nosotros vemos en la gloria algo superfluo, una futilidad. Un mexicano vivía poseído por ella del mismo modo que poseemos piernas (sin más historias), era algo que no se discutía y de donde provenía ese sentimiento de profunda ironía respecto a la vida humana (e incluso respecto a los dioses). La gloria era la única medida: estaba por encima de cualquier otra posibilidad y además hacía girar todo en torno a ella. El tumulto de las fiestas, lo mismo que el de las guerras, tenía un eficaz poder, análogo al de un corazón que late. Ponía al hombre y a cada uno de sus actos -incluso el más humilde- a la altura del Universo. Esta armonía animaba y fecundaba los trabajos del campo. El sentido mismo de las cosechas se expresaba en las danzas y los sacrificios. Los aztecas, lo mismo que otros pueblos primitivos, se equivocaban al conceder a sus ritos un poder análogo al de los trabajos agrícolas; no obstante su vida y sus cosechas estaban efectivamente relacionadas con los esplendores del cielo. Nada más lógico que atribuir fines espléndidos a la actividad económica: el reino de la pura necesidad es más profundamente hostil a la vida que el horror 
(...). Los sacrificios ponían en armonía al hombre con el universo. La fe en la eficacia de los ritos estaba en su base pero bastó para justificarlos con invertir el sentido: los mexicanos no podían hacer que la naturaleza les siguiese pero vivían de acuerdo con la naturaleza. (El límite de lo útil 29-30)

\section{Sobrenaturaleza}

En sintonía con esa propuesta, Lezama Lima se cuestiona acerca de la sobrenaturaleza en uno de sus últimos ensayos, "Confluencias" (1968), y allí afirma que la penetración de la imagen en la naturaleza ha engendrado la sobrenaturaleza, ocasión en que el mismo Lezama Lima cita una frase de Pascal que, por lo demás, le encantaba repetir ${ }^{7}$. Había anticipado esa idea en un ensayo de 1956, "Pascal y la poesía", argumentando la necesidad de restituir la naturaleza perdida, porque siempre hace falta crear mundos y no recibirlos como algo dado. "Como la verdadera naturaleza se ha perdido, dice Pascal, todo puede ser naturaleza", y agrega que "si la pérdida de la naturaleza se debió al pecado, no lo puede ser en el hombre el afán de colocar en el sitio de la naturaleza, después de la caída, otra naturaleza segregada o elaborada" (179). Entre los papeles inéditos y manuscritos del escritor cubano, se conservan unas anotaciones para una hipotética conferencia acerca de Paradiso (1966) en que constatamos su decisión de ir más allá de la noción heideggeriana de que el hombre es un ser para la muerte y substituirla por otra, la de que el poeta es el sujeto causa de la resurrección.

Los etruscos ofrecían una palabra misteriosa, el potens, si es posible, a esto se añade el hoc age, hazlo, es decir, si es posible, hazlo. El potens por la imagen hace posible la naturaleza. El potens al actuar en la infinitud engendra la imagen actuando en la sobrenaturaleza.

Para Lezama, por tanto, la poesía es la imagen generando la sobrenaturaleza, así como el poeta es quien toca ese espacio resistente como possibiliter, como posibilidad (Paradiso 710). La poesía, nos dirá Nancy, es presencia dotada de presencia (Les Muses 185). En otro ensayo, "La dignidad de la poesía", el mismo Lezama define al poeta como "guardián de la sustancia de lo inexistente como possibiliter", lo que explicaría que, ya en el período de Numa, hubiesen aparecido

7 "La vrai nature étant perdue, tout devient sa nature. Comme le véritable bien étant perdu, tout devient son véritable bien". Es el fragmento 345 de la edición de Hugh Fraser Stewart de los Pensamientos (Pascal. Pensées. With an English translation, brief notes and introduction by H. F. Stewart. Londres: Routledge y Kegan Paul, 1950, 188). 
entre los etruscos, esos eclécticos importadores simbólicos, el pontífice, el potens, aquél que, como Grandville, construye puentes saturninos con la descomunal fuerza condicional del si fuere posible, de modo que el virgo potens se transforma así en el alumbramiento de la infinita posibilidad. El catolicismo posterior se habría limitado apenas a proponer un pas au-delà del análogo prodigioso y del potencial infinito etrusco, con la salvedad de que no se trataría solamente de la resurrección de un dios, de un virgo potens específico, sino de todo un pueblo en la unanimidad; es decir que sería la resurrección del pueblo en la imagen como geometría del pensamiento de Dios (Tratados en La Habana 397). Desde ese punto de vista, válido en el caso lezamiano no sólo para la imagen sino para el gender o la escritura, tanto la generación en las tinieblas como la oikonomia (o encarnación entendida como proceso de la potencia) son las dos fuerzas aclamadas por el escritor cubano para salir del binarismo y el biologicismo. En La cantidad hechizada (28) Lezama Lima redunda la idea de que "existe un potens conocido en la poesía para que la causalidad actúe sobre lo incondicionado"; y en "La imagen histórica", otro de los ensayos de ese volumen, leeremos una reivindicación de la contingencia absoluta, aquello que puede no ocurrir, quidquid potest non fieri, en la medida en que lo imposible, al actuar sobre lo posible, crea un posible que a su vez actúa en lo infinito, de un modo que Marcel Duchamp, por la pluma de César Moro, no dudaría en llamar infraleve.

Para corroborar la imposibilidad del yo, Lezama Lima nos propone la persona como una tercera persona (Espósito, Terza persona), la personalidad como nadería, es decir, voluntad de potencia o, en otras palabras, voluntad de voluntad, acto eternamente repetido pero no menos revocado y así infinitamente potencializado. Entonces toda personalidad es una fuerza y mantiene con todas las otras personalidades diferentes relaciones de fuerza. Pero lo propio de la fuerza es ser plural, de allí que no se pueda pensar el conflicto social como un ejercicio argumentativo racional o dialéctico, del mismo modo que no es posible pensar esa fuerza, que es un sujeto, como simple individualidad acotada. El ser es singular-plural, es poder: es una cabeza, es un sujeto, es negatividad (la nada dialética, el néant fenomenológico), pero es también el objeto sobre el cual se ejerce un dominio, en la medida en que la nadería de la personalidad o el rien acefálico le dan nombre a la mera masa anónima. La acefalidad, esa nadería, es otro nombre para designar a la cultura. No en vano Lezama Lima registra, en su diario de lecturas, que prefería el concepto de vacío al de nada para traducir la noción de néant, recogida en Pascal o Valéry. El 12 de noviembre de 1939, por ejemplo, anota: 
La nada quedaría como la pura negación, mientras que el vacío sería un error manifiesto, bien un error nuestro, por falta de adecuación a ese vacío, o bien un momentáneo error del mundo exterior. Ver el vacío como el error pero no como el enemigo de toda creación. La nada es el imposible, mientras que el vacío puede ser salvado, penetrado algún día por la luz, por algún: hágase. La nada sólo pasa frente a un espejo que reproduce a la nada. El vacío, por el contrario, es el abismo de las primeras páginas de la Biblia. (...) La nada sería un castigo irredimible; mientras que el vacío parece referirse a que el conocimiento todavía no es infinito, pero puede ser tocado por la gracia, y entonces. (Diarios 25-26)

\section{La sobrenaturaleza como excedente de subsistencia}

Retomando la dialéctica del amo y el esclavo desarrolada por Hegel en La fenomenología del espíritu como lo otro de América Latina (Buck-Morss 2005), leemos, en la tesis 40 de La sociedad del espectáculo -libro que sólo una posición cerradamente autonomista podría calificar de envejecido o parcial, desmedido o sin fundamento (Miceli 29-34) - que el desarrollo de las fuerzas productivas, es decir, la historia real inconsciente, ha construido, según Guy Debord, las condiciones de existencia de los grupos humanos como condiciones de subsistencia y de expansión de esos mismos factores de determinación económica. El sector de la mercancía ha sido, en el interior de esa economía, un surplus de la survie, según Debord, o sea, un excedente de la subsistencia; una sobrenaturaleza. La producción de mercancías, que implica el cambio de diversos productos entre productores independientes aun cuando afectada por la industria, continuó siendo artesanal durante mucho tiempo, contenida en una función marginal cuya verdad sin embargo permanecía oculta. Pero allí donde encontró condiciones sociales de acumulación se apoderó totalmente del control sobre la economía, a tal punto que la misma economía se transformó en lo que la mercancía había mostrado ser: un proceso de desarrollo cuantitativo. Un tal despliegue de poder económico bajo la forma de la mercadería, transformando el trabajo humano en trabajo-mercancía -es decir, en salario-, desembocó en tamaña abundancia que la cuestión primaria de la subsistencia estaba, sin duda, resuelta, aunque de forma siempre parcial y recurrente, cada vez en un grado de mayor complejidad.

El crecimiento económico liberaba así a las sociedades de la presión natural que les imponía su lucha inmediata por la subsistencia, pero no les permitía que se liberasen de su liberador. La autonomía de la mercancía se extendía entonces al conjunto de la economía y, a continuación, Debord agrega un claro retournement 
de la idea de Pascal, idea rescatada también por Lezama Lima: la seudonaturaleza en la cual se ha alienado el trabajo humano exigía, por consiguiente, continuar su servicio hasta el infinito, pero ese servicio, que sólo puede ser abolido por sí mismo, obtiene la totalidad de los esfuerzos y de los proyectos socialmente lícitos como sus auténticos y más completos servidores. La abundancia de mercancías, concluye Debord, no puede ser más que la subsistencia aumentada. La consecuencia es clara: en la sociedad del espectáculo la imagen se ha vuelto ella misma una sobrenaturaleza, de suerte que la economía transforma el mundo pero lo transforma solamente en cuanto mundo de la economía, mundo de la imagen (Debord 37-38).

Para contrarrestarla, algunos artistas latinoamericanos, como Julio Le Parc con los laberintos activos del GRAV, asumen el arte-espectáculo como inversión de la situación anterior y activación de la participación del espectador en los circuitos (Danesi 180-182). En la filosofía se da otro tanto. Para Giorgio Agamben, heredero de las posiciones de Debord, el objetivo del pensamiento no puede ser, como lo era para la teoría crítica, un instante para añadir racionalidad al mundo. Al contrario, la racionalización productiva es la que nos ha encerrado en el atolladero. Se trata, entonces, de liberar energías -incluso las de las imágenespreviamente capturadas por los dispositivos biopolíticos e incluso bioestéticos, para restituirlas a un posible uso común. Particularmente en Profanaciones, aunque también en gran parte de su obra, Giorgio Agamben activa la potencia de un concepto como el de profanación. Para el filósofo italiano, en efecto, el capitalismo, llevando al extremo una tendencia presente ya en el cristianismo, generaliza y absolutiza, en cada ámbito de las actividades humanas, la estructura de la separación que define a la religión.

Allí donde el sacrificio señalaba el paso de lo profano a lo sagrado y de lo sagrado a lo profano, ahora hay un único, multiforme, incesante proceso de separación, que inviste cada cosa, cada lugar, cada actividad humana para dividirla de sí misma y que es completamente indiferente a la censura sacro/ profano, divino/humano. En su forma extrema, la religión capitalista realiza la pura forma de la separación, sin que haya nada que separar. Una profanación absoluta y sin residuos coincide ahora con una consagración igualmente vacua e integral. Y como en la mercancía la separación es inherente a la forma misma del objeto, que se escinde en valor de uso y valor de cambio y se transforma en un fetiche inaprensible, así ahora todo lo que es actuado, producido y vivido -incluso el cuerpo humano, incluso la sexualidad, incluso el lenguaje- son divididos de sí mismos y desplazados en una esfera separada que ya no define alguna división sustancial y en la cual cada uso se vuelve duraderamente imposible. Esta esfera es el consumo. Si, como se ha sugerido, 
llamamos espectáculo a la fase extrema del capitalismo que estamos viviendo, en la cual cada cosa es exhibida en su separación de sí misma, entonces espectáculos y consumo son las dos caras de una única imposibilidad de usar. Lo que no puede ser usado es, como tal, consignado al consumo o a la exhibición espectacular. Pero eso significa que profanar se ha vuelto imposible (...). Si profanar significa devolver al uso común lo que fue separado en la esfera de lo sagrado, la religión capitalista en su fase extrema apunta a la creación de un absolutamente Improfanable. (La potenza del pensiero 106-107)

Sintomáticamente, Lezama Lima registra en "Playas del árbol", conjunto de aforismos, fragmentos desgarrados de su diario que recogen una experiencia interior de lectura fechada en 1955 e incluida en Tratados en La Habana, algo relevante para este debate. Lezama pondera que, más importante que religare, lo substantivo es religiosus, el atributo, que él traduce, con Ortega y Gasset, como escrupuloso, celoso, meticuloso. Así pues, religioso sería el adversario de la negligencia. Profano, por el contrario, si acatamos esa etimología, sería el negligente (nec elegere), aquel que no elige, que no separa. A través de la alternativa negligente de Bartleby, Agamben no sólo nos mostraría que no hay religión sin separación; nos señalaría además el hecho de que toda separación -como la practicada por el capitalismo en su fase de sobrenaturaleza o espectáculo- contiene o conserva, en sí misma, un núcleo genuinamente religioso. El dispositivo que realiza y regula esa separación entre las esferas es el sacrificio y, en ese punto, Agamben retoma y expande el pensamiento de Marcel Mauss y discípulos como Alfred Métraux o Georges Bataille. Volvamos a ellos ${ }^{8}$.

En efecto, para la tradición heterológica la diferencia dimensional entre dos objetos, objetos idénticos, meros efectos de mecanización e industria, en nada artesanales ya que han perdido todo contacto con el hombre, esa diferencia se define como tiempo-con, es decir, al mismo tiempo, como mito y como rito. Desde la perspectiva del mito, la diferencia infraleve entre esos dos objetos, esas sobrenaturalezas que no pasan de imágenes, adopta culturalmente el movimiento de una escritura cuya productividad consiste, paradójicamente, no en la conservación sino en el gasto de su valor. Lo que cuenta en ellos es el movimiento entre una y otra imagen, entre una y otra instancia, por lo que el valor de la diferencia reposa en la impronta o huella de su desplazamiento. Ello expresa, de un lado, una religión, un entusiasmo, una identificación imaginaria de su creador con la

8 Retomo aquí ideas más cabalmente desarrolladas en "La acefalidad latinoamericana", ensayo incluido en Crítica acéfala 31-47. 
totalidad, pero, simultáneamente, manifiesta asimismo una profanación, un valor de expiación o desinstitucionalización a través de su productor, que así se depara con la clausura de la representación; es decir, con el límite de su misma acción, renunciando a la potencia vicaria de su agencia y, en última instancia, rechazando el elemento sagrado que aún residía en su poder de representación. Es en ese sentido que la diferencia infraleve funciona, en la lógica del artista que se concibe a sí mismo como un pequeño dios, alternativamente, como mito y como rito.

Pero desde la otra perspectiva, el punto de vista ritual-institucional, se podría pensar que el sujeto moderno, concebido a sí mismo como un transgresor simbólico nato, como alguien que expía los excesos del poder hasta encontrar los de la nuda vita (Agamben, Homo sacer), se dirige ciertamente al Otro, pero a un otro que no es ni un desconocido, ni alguien distante o exótico sino una pura alteridad, entendida como un simulacro de lenguaje, a la que pretende integrar en un rito desidealizado. El mito despilfarra lo que la institución atesora.

Como sabemos, Bataille articulaba en su concepto de parte maldita el sacrificio y la heterogeneidad. En una de las versiones desechadas de este último ensayo, admite su genealogía teórica argumentando que la sociología francesa, que siempre dio una gran importancia al estudio y a la interpretación del sacrificio, había solido vincular sus trabajos al concepto de ser social de Mauss. Este concepto, a menudo chocante -admite Bataille- se vuelve fácilmente admisible si uno reconoce que el ser es algo compuesto.

Un clan, una ciudad, un Estado, lo mismo que las personas, son seres que poseen una única conciencia. La idea de una "conciencia colectiva" no concuerda con los principios que hacen de la conciencia una entidad moral indivisible. Sin embargo estos principios son poco defendibles. La conciencia no es sin duda más que un campo de concentración (sic), el campo mal delimitado de una concentración siempre inacabada y nunca cerrada: no hace otra cosa más que reunir aquello que reflejan los múltiples espejos de la vida. Más concretamente todavía, aparece como una multiplicación de cada reflexión que se produce cuando esta reflexión, este juego de espejos, pasa de un punto a otro, de este hombre a aquél, lo mismo que de una célula sensible a otra. Es un juego al que no se le ve el final: siempre hay movimiento, actividad, tránsito. El ser, tal y como el hombre lo ha definido considerándose a sí mismo como tal, no está nunca presente como el guijarro del río sino como el flujo de las aguas, o mejor aún como el paso de la corriente eléctrica. Si existe alguna unidad en la presencia ésta obedece a torbellinos, a circuitos que se estabilizan y tienden a cerrarse. Yo me hago cargo fácilmente de lo que cambia en mí cuando comunico con otro, si hablo, si río, si me encuentro perdido 
en una reunión agitada. Y el primer llegado se hace cargo cuando abraza a la mujer que ama. Este cambio obedece al paso de una corriente de vida del uno al otro, pero estas transiciones tienen lugar en la mayoría de los casos sin formar circuitos estables, como lo son un clan, una ciudad o un Estado. Ahora bien, no hay ningún motivo para hablar del ser salvo que una subsistencia esté garantizada en el tiempo, como en el caso de una formación social que reúna a numerosos individuos. (El límite de lo útil 123-124)

Por ello, esa paradoja del tiempo-con, es decir, de la conservación aliada al gasto, lejos de ser exclusiva de la estética, se disemina fundamentalmente entre los regímenes políticos contemporáneos, cuya hegemonía, para perdurar, se apoya precisamente en masas excluidas de toda instancia de decisión, a tal punto que esos colectivos faltan en su lugar -el lugar del poder-al encontrarse disociado del deseo; es solamente un vacío infraleve, al que poco le importa si el administrador es "de derecha" o "de izquierda". La lógica de la exclusión incluyente todo lo atraviesa. Se plantea entonces, una vez más, la cuestión de la comunidad. Si ella es inconfesable (Blanchot) o incluso inoperante (Nancy), si más aún, como tantas veces dejó claro Derrida, si la comunidad no es más que un concepto al que debiéramos en verdad renunciar, ¿es posible pensar una comunidad plenamente comunitaria? ¿ $\mathrm{O}$ cabría pensar que la comunidad es tan sólo una de las categorías de lo impolítico? (Espósito 2006). Alain Badiou dice que no basta con desear la comunidad, hace falta postularla. Potens, hoc age. Esa creación, sin embargo, no logra deshacerse de su ambivalencia constitutiva y, a su juicio podríamos reconocer, de un lado, enunciados que niegan perentoriamente la equidad y que por su pragmatismo llamaríamos enunciados "de derecha", así como habría, frente a estos, otros juicios que, deseando la igualdad, adhieren programáticamente a ella, configurando una posición "de izquierda" (Badiou 121-127). Pero ¿hay sólo dos senderos? No parece ser ésa la opinión de Agamben.

Tal como el an-artista que resguarda la elección de la elección en el procedimiento estéticamente indiferente del ready-made, el autor de Profanaciones opta por no optar. Es negligente. Profana -vale decir-, adhiere y transgrede, converge y diverge. Sabe que aceptando la dicotomía de Badiou caería de algún modo en la teoría de la obra de arte elaborada por Benjamin en 1936, con sus perentorias opciones por la dualidad metafísica de la realidad material. Al contrario, si el sacrificio (según Benjamin el sacrifício del aura), a través de una serie de minuciosos rituales, sanciona el paso de lo profano a lo sagrado y de la esfera humana a la divina, Agamben tampoco ignora que lo que fue ritualmente separado puede muy bien ser restituido por el mismo ritual a la esfera profana. Por ello 
postula a la profanación como aquel contradispositivo encargado de restituir al uso común aquello que el sacrificio había separado y dividido previamente.

De ese modo, el capitalismo y el poder de la sobrenaturaleza, la acumulación y la imagen, parecen extremar los procesos separativos que definían a la religión en el mundo clásico. Si, acatando la propuesta de Agamben, asociamos la genealogía teológica de los dispositivos que los conecta al paradigma cristiano de la oikonomia, ya sea en la forma de la encarnación, como quería Lezama Lima, o del gobierno divino del mundo, según Agamben, se constata que los dispositivos modernos presentan, pese a todo, una diferencia en relación a los tradicionales, lo cual vuelve a la profanación algo particularmente problemático. En efecto, todo dispositivo implica un proceso de subjetivación, omnes et singulatim; de lo contrario, no podría funcionar como dispositivo de gobierno y se reduciría a mero ejercicio de violencia. Foucault nos llegó a mostrar que en una sociedad disciplinaria los dispositivos persiguen, a través de prácticas y discursos, de saberes y ejercicios, la creación de cuerpos dóciles aunque en última instancia libres, cuerpos que asumen su identidad y su autonomía en cuanto sujetos, en el proceso mismo de su paradojal sujeción a los dispositivos. Complementando esa idea con un concepto tomado de Furio Jesi, Agamben nos dice que el dispositivo es una máquina antropológica que produce subjetivaciones y sólo en esa medida es una máquina de gobierno (Calarco 163-167).

Según el filósofo, aquello que define a los dispositivos contemporáneos no es el hecho de que contribuyan a la producción de un sujeto, ni siquiera a un proceso que podríamos llamar de desubjetivación. Aunque en la alta modernidad ya existía un momento desubjetivante implícito en todo proceso de subjetivación, el presente del capitalismo se caracteriza por el hecho de que tanto los procesos de subjetivación como los procesos de desubjetivación se nos muestran recíprocamente indiferentes, sin dar lugar a la recomposición de un nuevo sujeto. En la no-verdad de un sujeto, según Agamben, ya no se encuentra más su verdad oculta porque, si todo dispositivo corresponde a un determinado proceso de subjetivación, hoy es absolutamente imposible afirmar que el sujeto del dispositivo lo use "de manera adecuada". No hay tal modo "correcto" y ni siquiera hay una norma previa para acomodarse a ella. La ley se conoce post factum. La causa es sencilla: las sociedades contemporáneas son cuerpos inertes atravesados por inmensos procesos de desubjetivación, que ya no corresponden a ninguna subjetivación efectiva, de allí el eclipse de la política, que siempre presuponía sujetos e identidades reales, dispuestos a la acción futura, y ello explica también el irresistible triunfo de la oikonomia, o sea, de una pura actividad de gobierno que no busca nada más allá de su misma reproducción o su puro goce (Signatura rerum 28-35). 
Voyou

Poco antes de la guerra, el poeta franco-rumano Benjamin Fondane (1898-1944), desaparecido en Auschwitz, sustentaba la tesis de que los poetas modernos habían recurrido, sistemáticamente, a procedimientos externos de intensificación de lo real tales como las drogas, la ascesis, el delirio o incluso la psicosis, para utilizarlos como dispositivos contragubernamentales, de refuerzo de la realidad que se había vuelto peligrosamente transparente. Querían así encontrar un equivalente a las participaciones afectivas del primitivo y para ello no dudaron en convocar a lo nuevo (Baudelaire), lo desconocido (Rimbaud), el hallazgo (Apollinaire), y por esa misma razón, que es una razón de ser, rompieron más tarde con el arte-imitación, inventaron la patafísica, gemela del psicoanálisis según Sollers, y, finalmente, alcanzaron la refutación, la abstracción del objeto (Faux Traité d'esthétique 104). Buena parte de esos recursos fueron utilizados por el mismo Fondane en su experiencia de cine experimental. Ahora bien, aun así, decía Fondane, artista muy atraído no sólo por el misticismo de Chestov y Berdiaeff sino por el Talmud, esas experiencias extremas del arte occidental no precipitaron grandes cambios de la sensibilidad porque el arte continuaba patinando, seguía tan vacío como antes del dadaísmo. Sabía no tener necesidad y esa ausencia de necesidad era, para el arte, mucho más nociva y perniciosa que la falta de solidez, reprochada por Platón, o la falta de densidad, achacada por Adorno (Faux Traité d'esthétique 105).

Fondane inició su lectura postmoderna de la modernidad a partir de su libro Rimbaud, le voyou (1933), es decir, "Rimbaud, el pillo". Acusando el uso, en el mismo título del libro, de un equivalente de las participaciones afectivas del primitivo -a través de la paronomasia voyant, vidente, y voyou, bandido-, Fondane nos revelaba la lógica profanatoria de la contemporaneidad que, no sin paradoja, lo elegiría a él como su próxima víctima. Al filmar la nada, su obsesión en los años de la crisis del capitalismo, Fondane fundía mito y rito de la negatividad y daba imagen a su techcatl particular, la piedra sacrificial de la soberanía. En efecto, voyou, más allá del uso hecho por Fondane como atributo del poeta sin cualidades, es un término que se popularizaría más tarde, en la política internacional de la Guerra Fría (1947-1989). El concepto de Etat voyou designa a un Estado-paria, un Estado fuera-de-la-ley. Así, según la política externa americana, el Rogue State es un Estado en ruptura de bando con las leyes internacionales, un Estado donde impera el terror, como la Camboya de Pol Pot, en los años 7o. Después el concepto pasó a designar a los Estados aislados del escenario internacional; aislados, aunque implicados asimismo en el armamentismo nuclear, hasta más recientemente en los 80 que se volvieron sinónimo de terrorista, tal es el caso de la Líbia de Kadafi. Anthony Lake, consejero de seguridad nacional de Clinton, 
publicó en 1994 un ensayo en la revista Foreign Affairs, "Backlash States", donde define a esos Estados como aquellos que -con una involuntaria metáfora benjaminiana- navegan a contrapelo de la Historia, porque son, simultáneamente, totalitarios y represivos, promueven ideologías radicales cuando no terroristas; se comportan de manera aislada y se pautan, fundamentalmente, por una profunda hostilidad con relación a Occidente. Noam Chomsky denunció, oportunamente, la flexibilidad de ese concepto geopolítico ya que en los últimos años las expresiones rogue o voyou fueron en fin substituidas por el eufemista concepto de state of concern, o sea, el Estado problemáticon ("L'Amérique, Etat voyou" 4-5). Nadie dudaría en atribuir al conjunto de los palestinos el atributo voyou.

En esa misma línea, Jacques Derrida desarrolló la indecibilidad del concepto en un libro de 2003, Voyous, en el que me voy a detener. Derrida argumenta allí que los únicos que pueden declarar la guerra a los Estados-bandidos son aquellos Estados cuya soberanía les permite abusar de las leyes. "Dès qu'il y a souveraineté, il y a abus de pouvoir et rogue State. L'abus est la loi de l'usage, telle est la loi même, telle est la logique d'une souveraineté qui ne peut régner que sans partage" (145). Es más: lo propio de la soberanía, podríamos decir, es tender, por tiempo limitado, a un equilibrio entre las partes, pero no le queda otra alternativa a esa soberanía excepcional que convertirse ella misma en una hegemonía imperial. "User de ce temps, c'est déjà abuser-comme le fait ici même le voyou que donc je suis. Il n'y a donc que des Etats voyous. En puissance ou en acte. L'Etat est voyou" (150). Y tamaña indecibilidad entre activo y pasivo, entre ley y fuera de la ley, entre sagrado y profano, sólo se explica, según Derrida, por los rumbos adoptados por la regulación jurídica internacional tras la Guerra Fría e incluso, de manera más acentuada, tras el 11 de septiembre ${ }^{9}$ ¿Qué cambia? Que la ruptura, inmaterial, no viene más del pasado sino del porvenir; la ruptura, que otros llaman acontecimiento, sólo habrá existido, como quería Mallarmé, cuando haya ocurrido. Esa inédita situación vuelve inviable una guerra internacional clásica pues ningún Estado quiere correr el riesgo de declarársela a los Estados 
Unidos, pero tampoco estimula la guerra de guerrillas porque no se trata más de liberar un Estado ocupado o invadido, como la Argelia del mismo Derrida (Nancy, L'independencce de l'Algérie... 65-70). Por ello mismo se impone, en la situación actual, abandonar ya, por improcedente, el concepto de terrorismo, siempre asociado a guerras revolucionarias, coloniales, de independencia o de partisanos. La nueva situación es, claramente, una profanación da la soberanía nacional moderna en que crecimos.

Para reforzar la realidad, vuelta transparente, el carácter voyou de la política externa se vuelve real, pero también interno y, como en las participaciones afectivas del primitivo, la cuestión se dirime en el exorcismo del lenguaje. Tal es el sentido de lo real para Lacan y, a su zaga, de la pasión de lo real de Badiou. Es por ello también que lo voyou se vuelve un caso -el caso Venezuela, el caso Cubagracias a otro término, caso (no menos denso por sus connotaciones médicas, psiquiátricas o jurídicas), lo cual nos revela, en última instancia, que el abandono de la política moderna nos conduce a la biopolítica y que ésta no pasa, en verdad, de tanatopolítica. Sin embargo -concluye Derrida- "le mot voyou fut envoyé, envoyé par le fond, son envoi a une histoire, et comme le mot rogue, il n'est pas éternel". Voyou y rogue sobrevivirán a los Etats voyous y a los rogue States que en realidad habrán precedido (155). El tiempo del concepto no sintoniza ya ni con un Estado ni con una acumulación; es el tiempo de una imagen, es el tiempo-con. Un razonamiento como ése nos muestra la relevancia que para el último Derrida adquiere la noción de sombra o revenant, que no pasa en realidad de una fantasía arcaica: la política determinó el voyou, vació ese significante rimbaudiano, lo abandonó, pero la palabra sobrevivirá como fantasma a la cultura que la engendró. Leer, como dice Lévy-Bruhl en La mentalidad primitiva, es cambiar de religión. Leer es recoger el fantasma de otro tiempo que, sin embargo, es un tiempo aún por-venir.

Vemos, por tanto, que una participación afectiva de lo primitivo, como la que llevó a Fondane, por ejemplo, a explorar la experiencia poética moderna mediante el recurso del instrumento existencial nihilista de Léon Chestov, nos condujo casi involuntariamente a la experiencia política de disociar, de separar, de profanar, los conceptos de soberanía y de incondicionalidad de la norma jurídica. Mal puede hoy día esperarse, entonces, una reconciliación de la soberanía con el discurso del derecho ya que, entre ambas, debiéramos hablar no exactamente de imperio de la ley sino de una norma que se monta como impostura o comedia del poder.

La vanguardia, como la de Fondane, rompió con la clausura ontológica del poema y con el idealismo de la imagen, refutando la herencia platónica el 
estetismo, la artificialidad, el abandono de los valores vitales a través de una consecuente exploración de las potencialidades afectivas: la contingencia, el pathos, la velocidad, lo aleatorio. En el centro del escenario, en vez de la mímesis de la realidad pasamos a tener la mimología del lenguaje; en vez del poeta legislador, el poeta profanador, un Mimo, idéntico al Ángel benjaminiano de la Historia. Para ese voyou, el dadaismo había montado la pantomima cósmica de una anarquía universal cuyo héroe, sin duda, era aún Rimbaud. En 1919, Francis Picabia publica el poema Pensées sans langage. Pensamentos de pura habla, sin pueblo, pensamientos por-venir. Allí se lee, por ejemplo:

Aucun mystère femme antichambre

Tu empestes la plisanterie

Dans le sommeil des persiennes closes

Égratignées d'un regard voyou $(41)^{10}$

Las persianas, como las pupilas de Girondo o Drummond, cerradas, heridas por una mirada bandida, aislada, neutralizada. Pero a Fondane, no menos aislado o neutralizado, no se le escapaba que no sólo en el caso del voyou sino, más ampliamente, en el del lenguaje como un todo, hemos sido traicionados por palabras a las que les dimos aliento, simplemente porque "longtemps nous avons pris les mots pour du réel" ("Signification de Dada" 16). A esas alturas, indudablemente, la teoría estética del voyant, que es la teoría vanguardista de la transgresión ante una ley relativamente fija o territorializada, cedía su lugar a la teoría política del voyou, una caída catastrófica que nos revela el vacío, el punto de la nada, la línea de sombra, ese real singular, contingente y finito que, a través de la profanación, se impuso a nuestra consideración. Pasamos, en suma, del placer al goce, de la naturaleza a la sobrenaturaleza.

Bataille vinculó el Quetzalcóatl con una figura de historieta de los años 30, los Pieds nickelés, a los que leía atendiendo al anacronismo de las imágenes y asociándolos a una palabra desprovista de sentido, una palabra sin lengua, una experiencia dadá. Así argumentaba que "si otorgamos al entretenimiento un sentido suficientemente mejicano, es decir una intervención siempre más o menos extemporánea en los dominios más serios, el entretenimiento todavía puede parecer como la única reducción del idealismo" (Les pieds nickelés 215-6). Una lectura caleidoscópica del presente nos revela no exactamente la historia, es decir, lo que pasa en los hechos, sino la historicidad, el umbral de nuestro esquivo presente.

10 Traduzco: "Ningún misterio mujer antecámara / Empestás los cumplidos / Durante el sueño de persianas cerradas / Heridas por una mirada bandida". 
En esa explosión de la cronología reconocemos una participación temporal en la temporalidad, una hiper-temporalización, infinita y potencializada, del evento singular irradiante. Es lo necesario para salir del callejón de la autonomía.

\section{Obras citadas}

Agamben, Giorgio. "L'origine e l'oblio". Risalire il Nilo. Mito fiaba allegoria.

Eds. Ferruccio Masani y Giulio Schiavoni. Palermo: Sellerio, 1974.

-. Homo sacer: Il potere sovrano e la nuda vita I. Turín: Einaudi, 1995.

-. Image et mémoire. París: Hoëbeke, 1998.

-. "Identificación y desidentificación de un autor llamado José Bergamin". Archipélago. Cuadernos de crítica de la cultura (abril-mayo 2001).

-. La potenza del pensiero. Saggi e conferenze. Vicenza: Neri Pozza, 2005.

-. Che cos'è un dispositivo? Roma: Nottetempo, 2006.

-. Ninfe. Torino: Bollati Boringhieri, 2007.

-. Signatura rerum. Sul metodo. Torino: Bollati Boringhieri, 2008.

-. Cos ề il contemporaneo? Roma: nottetempo, 2008.

Antelo, Raúl. Crítica acéfala. Buenos Aires: Grumo, 2008.

—. "La des-obra como ready-made". Quimeras. Cuando la literatura sabe, ve, piensa. Cahiers de LI.RI.CO (2008): 17-31.

Appadurai, Arjun. La modernidad desbordada: dimensiones culturales de la globalización. Buenos Aires: Trilce, 2001.

Badiou, Alain. Abrégé de Métapolitique. París: Seuil, 1998.

Bataille, Georges. "Les Pieds nickelés". Documents, París, 1930. 215-216.

—. Oeuvres Complètes. París: Gallimard, 1971.

-. "El arte, ejercicio de crueldad". La felicidad, el erotismo y la literatura. Ensayos 1944-1961. Buenos Aires: Adriana Hidalgo, 2001.

- L L o oscuridad no miente. Textos y apuntes para la continuación de la Summa ateológica. Selección, traducción y epílogo de Ignacio Díaz de la Serna. México: Taurus, 2001.

- El límite de lo útil (fragmentos de una versión abandonada de $L a$ Parte maldita). Trad. Manuel Arranz. Madrid: Losada, 2005.

Fondane, Benjamin. Rimbaud le voyou. Paris: Denoel et Steele, 1933.

Buck Morss, Susan. Hegel y Haiti. La dialéctica amo-esclavo: una interpretación revolucionaria. Trad. F. Rodríguez. Buenos Aires: Norma, 2005.

Calarco, Matthew. "Jamming the Anthropological Machine". Giorgio Agamben. Sovereignity and Life. Stanford: Stanford University Press, 2007. 163-179.

Chomsky, Noam. "Rogue States". Z Magazine (1998, abril).

—. "L'Amérique, Etat voyou". Le Monde Diplomatique (2000, agosto). 
Danesi, Fabrien. Le mythe brisé de l'Internationale Situationiste. L'aventure d'une avant-garde au coeur de la culture de masse (1945-2008). Dijon: Les Presses du réel, 2008.

Debord, Guy. La Société du Spectacle. París: Gallimard, 1992.

Derrida, Jacques. "Mes chances. Au rendez-vous de quelques stéréophonies épicuriennes". Psyché, inventions de l'autre. París: Galilée, 1987. 353-384.

—. Voyous. París: Galilée, 2003.

Didi-Huberman, Georges. Cuando las imágenes toman posición. El ojo de la historia. Vol. 1. Trad. Inés Bértolo. Madrid: A. Machado, 2008.

-. Lo que vemos, lo que nos mira. Buenos Aires: Manantial, 2004.

-. La distancia y la huella: para una antropología de la mirada. Cuenca: Diputación Provincial, 2001.

Duthuit, Georges. "Representations de la mort". Cahiers d'Art 1939. 25-39.

Espósito, Roberto. Categorías de lo impolítico. Trad. R.

Raschella. Buenos Aires: Katz, 2006.

-.Terza persona. Politica della vita e filosofia dell'impersonale. Torino: Einaudi, 2007.

Fondane, Benjamin. Faux Traité d'esthétique. París: Mediterranée, 1998.

-."Signification de Dada", Fondane et l'Avant-Garde. Ed. Michel

Carassou y P. Petre Raileanu. París: Méditerranée, 1999• 32-36.

Foucault, Michel. "Theatrum philosophicum". Dits et

écrits. Vol. 2. París: Gallimard, 1994. 75-99.

Herve, Roger. "Sacrifices Humains du Centre-Amérique".

Documents, París, 1930. 205-2013.

Koenigswakd, Ralph Von. "Têtes et crânes". Documents. París, 1930. 353-358.

Leiris, Michel. "Le caput mortuum ou la femme de l'alchimiste". Documents, 1930.

Lévy-Bruhl, Luden. La mentalité primitive. The Herbert Spencer

Lecture 1931. Oxford: Clarendon Press, 1931. 2126-2130.

Lezama Lima, José. Tratados en La Habana. La Habana:

Universidad Central de las Villas, 1958.

-. La cantidad hechizada. La Habana: Unión, 1970.

-. Paradiso. Ed. crítica Cintio Vitier. Buenos Aires: Fondo de Cultura Económica-UNESCO, 1993.

-. Diarios (1939-1949/ 1956-58). Ed. Ciro Bianchi Ross. México: Era, 1994.

Métraux, Alfred. "Un mundo perdido: la tribu de los chipayas de Carangas". Sur (invierno 1939): 98-131.

—. "Arribo a la isla de Pascua". Sur (septiembre 1941): 39-52.

—. La isla de Páscua. Trad.Emili Olcina. Barcelona: Laertes, 1995. 
Miceli, Sérgio. "Espetáculo sem sociedade". Observatório

Itaú Cultural (julio-septiembre 2008): 29-34.

Nancy,Jean-Luc. Les Muses. París: Galilée, 1994.

- L L creación del mundo o la mundialización. Trad.

Pablo Velamazán. Barcelona: Paidós, 2003.

—. "Fazer, a poesia". Resistência da poesia. Lisboa: Vendaval, 2005.

—. Del libro e della librería. Il commercio delle idee. Milán: Raffaello Cortina, 2006.

—. "L'independencce de l'Algérie et l'indipendence de Derrida" en Cités 2007.

Pascal. Pensées. With an English translation, brief notes and introduction

by H. F. Stewart. Londres: Routledge \& Kegan Paul, 1950.

Picabia, Francis. Pensées sans langage: Poème. París: Eugène Figuière, 1919.

Rella, Franco. Pensar per figure. Freud, Platone, Kafka il postumano. Roma: Fazi, 2004. 